DEVELOPMENTAL GENETICS

\section{Space-time continuum}

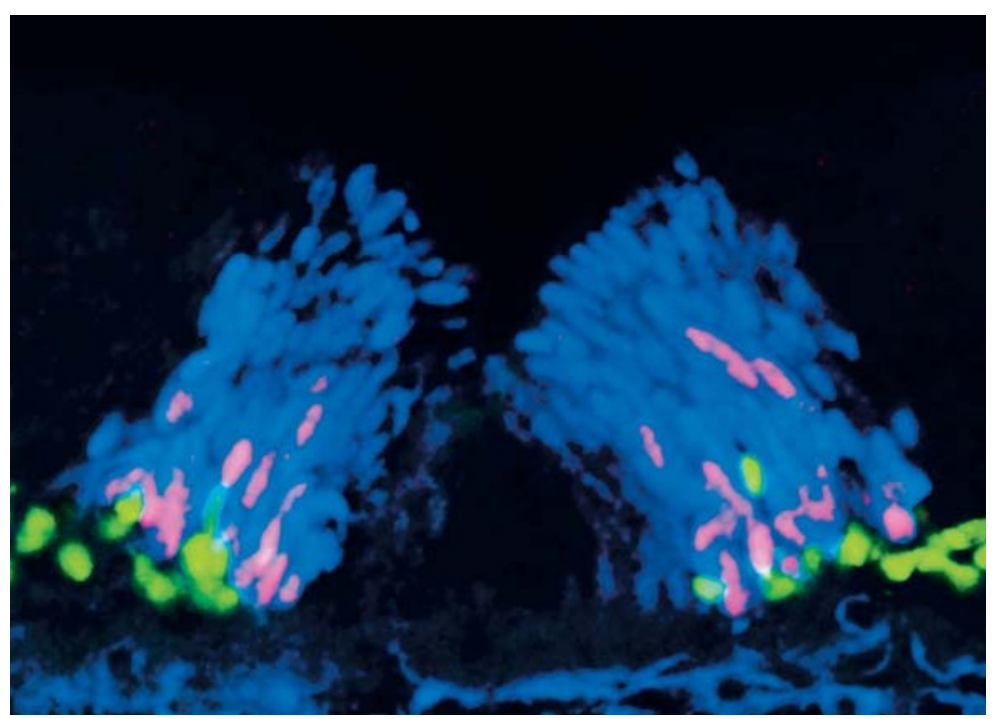

Cross section of a mouse hindbrain at embryonic day 11. The vMNs (green) are migrating away from the neurogenic zone (blue), which is generating 5-HT neurons (pink). Courtesy of J. Ericson, Karolinska Institute, Stockholm, Sweden.
The ventral hindbrain of the vertebrate embryo contains a population of neuronal progenitor cells that gives rise to visceral motor neurons (vMNs) and serotonergic (5-HT) neurons. Each hindbrain segment, or rhombomere, initially generates vMNs, but all the rhombomeres except for $\mathrm{r} 4$ switch to producing 5HT neurons at a defined time point (around embryonic day 10.5 in the mouse). These observations raise two crucial questions - how do progenitors switch from vMN to 5-HT neuron production, and how is $\mathrm{r} 4 \mathrm{pre-}$ vented from making this switch? In Genes and Development, Pattyn and colleagues show that the answers might lie with a set of homeobox genes that are also important for the spatial patterning of the hindbrain.

The Phox $2 b$ gene is required for the generation of vMNs in the hindbrain, and Pattyn et al. found that in $\mathrm{r} 2-\mathrm{r} 3$ and r5-r7, the switch from vMN to 5 -HT neuron generation coincides with downregulation of Phox $2 b$ in the ventral portion of each rhombomere. In $\mathrm{r} 4$, on the other hand, Phox $2 b$ expression is maintained at all dorsoventral levels. Another feature that distinguishes $\mathrm{r} 4$ from the other rhombomeres is its expression of Hoxb1, and the authors showed that $\mathrm{r} 4$ can generate 5-HT neurons in Hoxb1 mutant embryos. Nkx6.1 and 6.2 are required to maintain Hoxb1 expression in the ventral part of $\mathrm{r} 4$ in their absence, the Hoxb1 expression domain recedes dorsally, and $\mathrm{r} 4$ begins to generate 5-HT neurons at around the same time. This indicates that Hoxb1 suppresses the switch to 5 -HT neuron production. Its importance was underlined in Hoxb2 mutant embryos, in which Hoxb1 is downregulated in the ventral part of r4, but later than in the $N k x 6$ mutants. In these embryos, $\mathrm{r} 4$ generates fewer 5 -HT neurons than in the $N k x 6$ mutants, implying that production of these neurons begins later, commensurate with the downregulation of Hoxbl.

\title{
DEVELOPMENTAL GENETICS
}

\section{Wizard of clocks}

Finding out exactly what is pulling the levers that control the vertebrate segmentation clock has turned out to be as surprising as it was for Dorothy when she pulled back the curtain to reveal the real Wizard of Oz. Alexander Aulehla and colleagues in their new study, published in Developmental Cell, show that Wnt3a has a key role in the clock that controls segmentation.

It is only recently that molecular evidence has emerged to show that a segmentation clock and a molecular gradient in the presomitic mesoderm (PSM) are involved in formation of the precursors to vertebrae - the somites. The next step was to find genes the expression of which oscillates in a clocklike fashion and which have a graded expression pattern in the PSM.

Using in situ hybridization screening on whole-mount mouse embryos, Aulehla et al. identified a completely unexpected candidate that meets these criteria -
Axin2, a negative regulator in the Wnt $/ \beta$-catenin signalling cascade. This first link between the $W n t / \beta$-catenin pathway and the segmentation process is a neat result in itself, but the authors went on to show that Axin2 is unique in that it cycles out of phase from the other cycling genes and, unlike them, continues to cycle even when Notch signalling is impaired.

So, if it is not Notch signalling, what is controlling Axin2 expression? With a reporter-gene assay that shows that a dominant active form of $\beta$-catenin strongly activates the Axin 2 promoter, the authors provide convincing evidence that Axin2 is under the direct control of $\mathrm{Wnt} / \beta$-catenin signalling. An in vivo reporter assay showed that mutating Lef/Tcf binding sites abolished the characteristic Axin2-like expression pattern of the reporter gene in structures derived from the PSM.

However, Aulehla and colleagues really start to pull that curtain back by showing that in embryos with reduced expression of Wnt $3 a$, Axin 2 is strongly downregulated in the tailbud and PSM, as is $L f n g$, which is a cycling gene that is a direct target of Notch signalling. Coupled with further in vivo data that show the importance of Wnt3a in somitogenesis, these results downgrade Notch signalling to an intermediate link in the chain and show that Wnt $3 a$, through Axin2, is probably pulling the levers.

The authors present a plausible model for the segmentation process based on Wnt signalling that can explain the segmentation clock and the PSM gradient. Their model will, of course, need testing, but at least now we know to focus on $W n t 3 a$, the little guy behind the curtain, rather than the booming voice of Notch signalling.

Nick Campbell

\section{(2) References and links} ORIGINAL RESEARCH PAPER Aulehla, A. et al. Wnt3a plays a major role in the segmentation clock controlling somitogenesis. Dev. Cell 4, 395-406 (2003) FURTHER READING Saga, Y. \& Takeda, H. The making of the somite: molecular events in vertebrate segmentation Nature Rev. Genet. 2, 835-845 (2001) WEB SITE

Bernhard Herrmann's laboratory:

http://www.immunbio.mpg.de/home/englisch/index.html 